\title{
Overview of the European framework for online integrated air quality and meteorology modelling (EuMetChem)
}

\author{
Alexander Baklanov ${ }^{1,2}$ \\ ${ }^{1}$ World Meteorological Organization, Geneva, Switzerland \\ ${ }^{2}$ Danish Meteorological Institute, Copenhagen, Denmark \\ Correspondence to: Alexander Baklanov (abaklanov@wmo.int)
}

Published: 10 May 2017

\begin{abstract}
The COST Action ES1004 - European framework for online integrated air quality and meteorology modelling (EuMetChem) is focusing on a new generation of online integrated Atmospheric Chemical Transport (ACT) and Meteorology (Numerical Weather Prediction and Climate) models with two-way interactions between different atmospheric processes including chemistry (both gases and aerosols), clouds, radiation, turbulent mixing, emissions, meteorology and climate. Two major application areas of the integrated modelling are considered: (i) improved numerical meteorology and weather prediction (NWP) and chemical weather forecasting (CWF) with short-term feedbacks of aerosols and chemistry on meteorological variables, and (ii) twoway interactions between atmospheric pollution/composition and climate variability/change. The framework consists of 4 working groups namely: (1) Strategy and framework for online integrated modelling; (2) Interactions, parametrizations and feedback mechanisms; (3) Chemical data assimilation in integrated models; and (4) Evaluation, validation, and applications. Establishment of such an European framework (involving also key American experts) enables the EU to develop world class capabilities in integrated ACT/NWPClimate modelling systems, including research, education and forecasting. This article provides an introduction to the EuMetChem goals and outcomes for this Special Issue "Coupled chemistry-meteorology modelling: status and relevance for numerical weather prediction, air quality and climate communities (SI of EuMetChem COST ES1004)" which collects key scientific papers of EuMetChem and its collaborators from different continents.
\end{abstract}

\section{COST Action ES1004 EuMetChem Overview}

Motivation to start the $\operatorname{COST}^{1}$ Action ES1004 "European Framework for Online Integrated Air Quality and Meteorology Modelling (EuMetChem)" arose from results of off-line coupled Numerical Weather Prediction (Meteorological) and Air Quality Models and the online coupled models (Fig. 1). Experimental studies and research simulations have shown that atmospheric processes (meteorological weather, including precipitation, thunderstorms, radiation, clouds, fog, visibility and PBL structure) depend on concentrations of chemical components (especially aerosols) in the atmosphere. Furthermore, meteorological data assimilation (in particular assimilation of radiances) depends on the chemical composition. Last not least, studies also have shown that air quality forecasts loose accuracy when ACT models are run offline. However, a new generation of online integrated meteorology and chemistry modelling systems is becoming available for predicting atmospheric composition, meteorology and climate change.

Historically Europe has not adopted a community approach to modelling and this has led to a large number of model development programmes, usually working independently. Besides AQ and NWP communities worked independently. Needed is a strategic framework that will help to provide a common goal and direction to European research in this field while having multiple models. The COST Action was initiated to integrate, streamline and harmonize the interaction between atmospheric chemistry modellers, weather

\footnotetext{
${ }^{1}$ COST - European Cooperation in Science and Technology, http://www.cost.eu/. COST is the longest-running European framework supporting trans-national cooperation among researchers, engineers and scholars across Europe.
} 


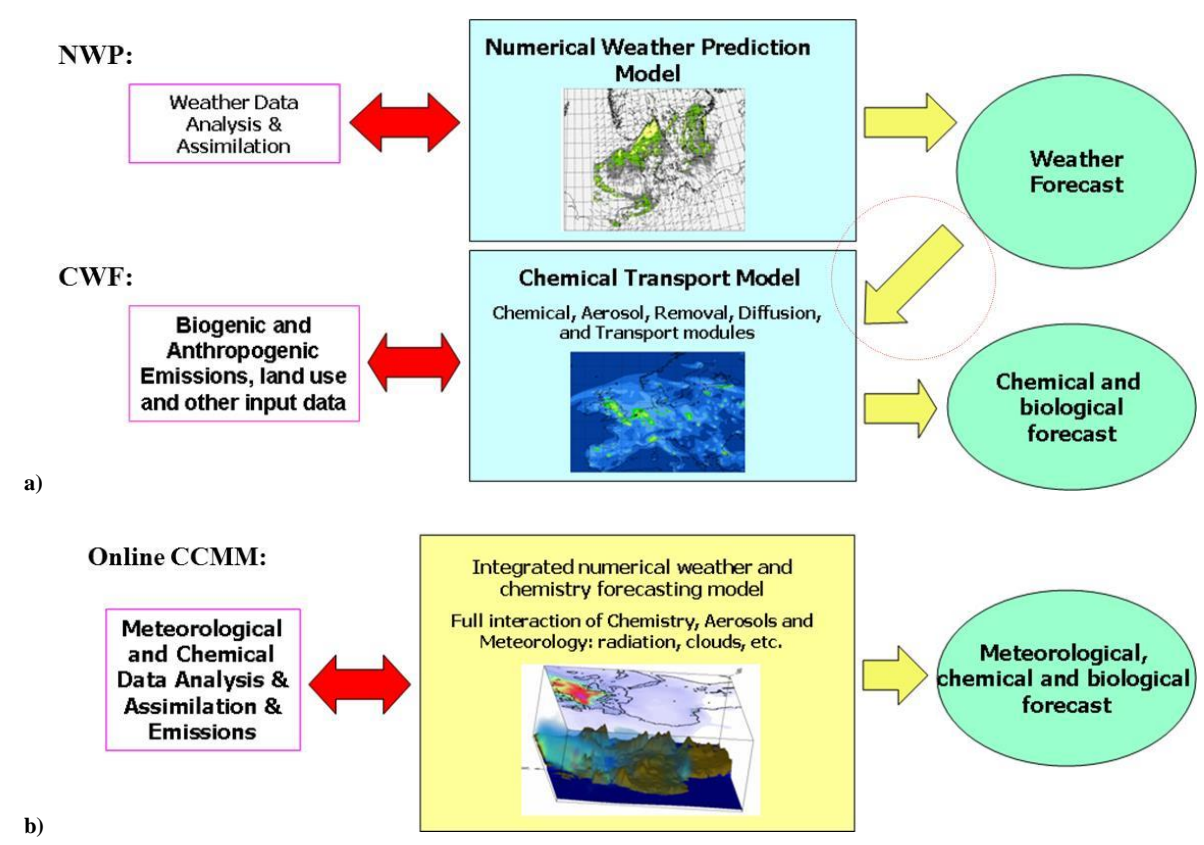

Figure 1. Schematic diagram of (a) offline and (b) online (CCMM) coupled NWP and CWF modelling approaches for atmospheric composition and meteorology simulation.

modellers and end users. It will lead to strongly integrated and unified tools for a wide community of scientists and users.

The European COST Action ES1004 EuMetChem (European Framework for Online Integrated Air Quality and Meteorology Modelling; 2011-2015) aimed at developing a strategy and framework for online integrated modeling by identifying relevant interactions, parameterizations and feedback mechanisms and considering chemical data assimilation in integrated models. It considered the new generation of online models, using integrated Atmospheric Chemical Transport (ACT) and Meteorology (Numerical Weather Prediction and Climate) modelling with two-way interactions between different atmospheric processes including chemistry (both gases and aerosol), clouds, radiation, boundary layer, emissions, meteorology and climate. Overall objective was to set up a multi-disciplinary forum for online integrated air quality/meteorology modelling and elaboration of the European strategy for a new generation integrated ACT/NWP-Climate modelling capability/framework.

Main topics were:

1. Online versus offline modelling: advantages and disadvantages,

2. Analysis of priorities, particularly focusing on interaction/feedback mechanisms,

3. Chemical data assimilation in integrated models,

4. European strategy/framework/centre for online integrated modelling,
5. Evaluation and validation framework of online ACT/NWP-Climate models,

6. Collection of suitable datasets for model development and evaluation.

The EuMetChem action included experts not only from Europe but also from other continents (Fig. 2) to take advantage of the global expertise in this dynamic research field. It involved teams from 23 European COST countries: Austria, Bulgaria, Denmark, Estonia, Finland, France, Germany, Greece, Hungary, Israel, Italy, Malta, Netherlands, Norway, Poland, Portugal, Serbia, Slovenia, Spain, Sweden, Switzerland, Turkey, United Kingdom and several institutions from non-COST countries (Argentina, Brazil, Canada, Egypt, Russia, Ukraine, USA) and international organizations (ECMWF, EEA, JRC, WMO) contributing with their expertise. The chair of the Action was Prof. Alexander Baklanov, Danish Meteorological Institute (now at WMO), the vice-chars were Prof. Sylvain Joffre, Finnish Meteorological Institute, and Prof. K. Heinke Schlünzen, University of Hamburg, Germany, the grant holder representative was Prof. Nicolas Moussiopoulos, AUTH, Greece.

EuMetChem research activities are organized within the following four Working Groups (WGs names and leaders):

- WG1: Strategy and framework for online integrated modelling (coordinated by Dr. Peter Suppan, Karlsruhe Institute of Technology and Prof. Jose M. Baldasano, Barcelona Supercomputing Center, advised by Dr. Georg Grell, NOAA), 


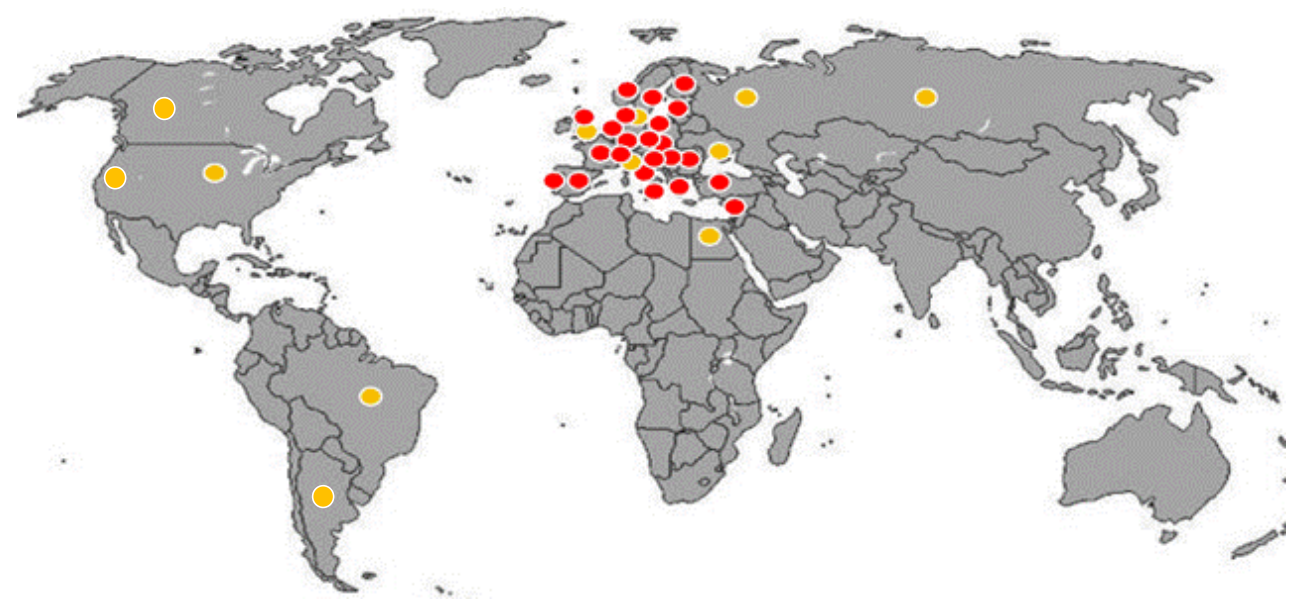

Figure 2. European COST countries EuMetChem members (red dots) and other institutions (yellow dots) contributing with their expertise to the COST Action ES1004 EuMetChem.

- WG2: Interactions, parameterizations and feedback mechanisms (coordinated by Dr. Michael Gauss, met.no, Dr. Alberto Maurizi, Institute of Atmospheric Sciences and Climate, Italian National Research Council and since March 2014 Dr. Renate Forkel, Karlsruher Institut für Technologie, advised by Prof. Yang Zhang, North Caroline University)

- WG3: Chemical data assimilation in integrated models (coordinated by Prof. Christian Seigneur, CEREA, Université Paris-Est, France and Dr. Hendrik Elbern, University of Cologne, advised by Prof. Greg Carmichael, University of Iowa),

- WG4: Evaluation, validation, and applications (coordinated by Dr. Dominic Brunner, Empa, Swiss Federal Laboratories for Materials Science and Technology, Dr. Stefano Galmarini, JRC EC, Ispra and Prof. Heinke Schluenzen, University of Hamburg, advised by Dr. S. T. Rao, US EPA).

The following key scientific questions have been formulated in COST ES1004:

- What are the effects of climate/meteorology on the abundance and properties (chemical, microphysical, and radiative) of aerosols on urban/regional scales?

- What are the effects of aerosols on urban/regional climate/meteorology and their relative importance (e.g., anthropogenic vs. natural)?

- How important are the two-way/chain feedbacks among meteorology, climate, and air quality in the estimated effects?

- What is the relative importance of aerosol direct and indirect effects as well as of gas-aerosol interactions in the estimates on different spatial and temporal scales?
- What are the key uncertainties associated with model predictions of mentioned effects?

- How to realize chemical data assimilation in integrated models for improving NWP and CWF?

- How can simulated feedbacks be verified with available observations/datasets?

Online coupled meteorology atmospheric chemistry models have undergone a rapid evolution in recent years. Developments of the coupled atmosphere-chemistry models and consideration of aerosol feedbacks are realized in different research communities, first of all in the air quality modelling, numerical weather prediction and climate modelling as they can consider not only the effects of meteorology on air quality, but also the potentially important effects of atmospheric composition on weather. Relative importance of online integration and of the priorities, requirements and level of details necessary for representing different processes and feedbacks can greatly vary for these related communities.

Some outcomes of the EuMetChem COST Action ES1004 are reflected in:

- Joint overall review paper with all participants and a wider community involved (Baklanov et al., 2014);

- Two Summer schools on CCMM: in Odessa, Ukraine (2011) and in Aveiro, Portugal (2014), the last one with more than 200 applications and 52 students from 25 countries of 4 continents and with publication of training materials (Miranda et al., 2014);

- Participation in the join AQMEII Phase2 model exercise coordinating its European efforts and performing various modelling runs (Galmarini and Hogrefe, 2015); 


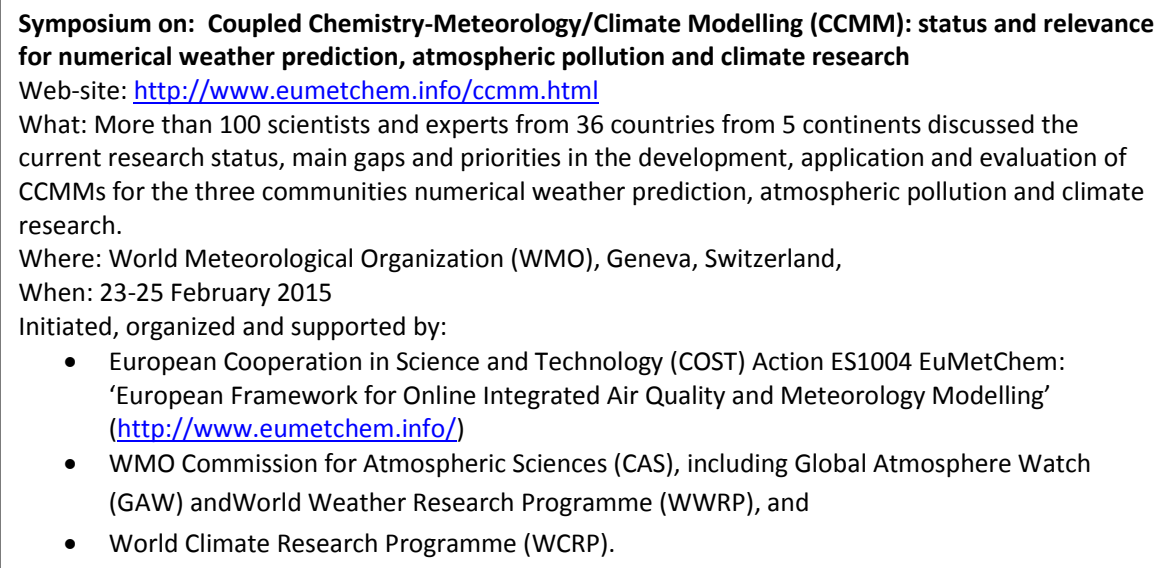

- European Cooperation in Science and Technology (COST) Action ES1004 EuMetChem: 'European Framework for Online Integrated Air Quality and Meteorology Modelling' (http://www.eumetchem.info/)

- WMO Commission for Atmospheric Sciences (CAS), including Global Atmosphere Watch (GAW) andWorld Weather Research Programme (WWRP), and

- World Climate Research Programme (WCRP).

Figure 3. Short summary in the CCMM symposium.

- Multiple publications, workshops and short-term scientific missions (See Publications of EuMetChem below and in CCMM, 2016);

- Action was attractive to many scientists outside the action (including overseas, Fig. 2);

- Attraction to WMO for participation in the final EuMetChem scientific conference (CCMM, 2016);

- Triggering of WMO initiative on seamless prediction (Chap. 12 in WWRP, 2015);

- This integrated Special Issue of Atmospheric Chemistry and Physics/Geoscientific Model Development journals on "Coupled chemistry-meteorology modelling: status and relevance for numerical weather prediction, air quality and climate communities" (Baklanov et al., 2013).

The status of integrated modeling has extensively been summarized by EuMetChem in Baklanov et al. (2014) and a large number of regional model systems have been thoroughly evaluated in the joint European - North American initiative AQMEII-2 (Galmarini et al., 2015).

The main findings from the COST ES1004 action with recommendations for scientists, users and international organizations and suggested answers on the key scientific questions are presented in many papers of this Special Issue (Baklanov et al., 2013), CCMM overview article (Baklanov et al., 2017) and WMO-EuMetChem report (CCMM, 2016). This Special Issue and the short summary below and the conclusions and recommendations shall also help scientists, experts and students interested in this quickly developing field to understand the results of this action and which steps should be taken next (e.g. needed research).

\section{EuMetChem Symposium on Coupled Chemistry-Meteorology/Climate Modelling}

The Symposium on "Coupled ChemistryMeteorology/Climate Modelling (CCMM): status and relevance for numerical weather prediction, atmospheric pollution and climate research", was initiated/organized by EuMetChem as its final event and was strongly supported by WMO. It brought together more than 100 experts (Fig. 3) from three different research communities interested in CCMM modeling, that is air quality (AQ), numerical weather prediction (NWP) and climate change (CC), with the aim to review the current status of CCMM modeling and assess the processes relevant for the interactions between atmospheric physics, dynamics and composition. In addition, it highlighted scientific issues and emerging challenges that require proper consideration to improve the reliability and usability of these models for AQ, NWP, and CC. It presented a synthesis of scientific progress and provided recommendations for future research directions and priorities in the development, application and evaluation of seamless online coupled models.

The main focus of the symposium was on aerosols and their feedbacks with weather and climate. The following specific topics were covered:

- Coupled chemistry-meteorology (weather and climate) modeling $(\mathrm{CCMM})$ : approaches and requirements;

- Key processes of chemistry-meteorology interactions and their descriptions;

- Aerosol effects on meteorological processes and numerical weather prediction;

- CCMM for air quality and atmospheric composition;

- CCMM for regional and global climate modeling; 
- Model validation and evaluation;

- Data requirements, use of observations and data assimilation;

- Outlook and future challenges.

Additionally to the main oral and poster sessions, a plenary discussion session was organized and seven brain storming teams reported their outcomes on the following topics: (1) Coupled chemistry-meteorology systems (Greg Carmichael (chair), Georg Grell, Peter Suppan, Alexander Baklanov), (2) Key processes (Bernhard Vogel (chair), Paul Makar, Renate Forkel, Yang Zhang), (3) CCMMs for climate studies (Øystein Hov (chair), Michel Rixen, Michael Gauss, Annica Ekman, Michaela Hegglin), (4) CCMMs for air quality and atmospheric composition (Rohit Mathur (chair), Veronique Bouchet, Nicolas Moussiopoulos, Jose M. Baldasano, Ana Isabel Miranda), (5) CCMMs for NWP and meteorology (Saulo Freitas (chair), Sylvain Joffre, Vincent-Henri Peuch, Nick Savage), (6) Model evaluation (Heinke Schlünzen (chair), Dominik Brunner, S. T. Rao, Stefano Galmarini, (7) Data assimilation (Christian Seigneur (chair), Johannes Flemming).

Reports of these groups and further symposium material and outcomes are published as the WMO Report (CCMM, 2016) and selected papers presented at the conference are contributing to this joint CCMM/EuMetChem special issue of Atmospheric Chemistry and Physics and Geoscientific Model Development (Baklanov et al., 2013). Most of the presentations of the symposium are available through the website of the COST Action ES1004: http://www.eumetchem. info/ccmm.html.

A summary of the key issues and recommendations regarding Coupled Chemistry-Meteorology/Climate Modeling: status and relevance for numerical weather prediction, atmospheric pollution and climate research based on the symposium presentations, discussions and conclusions of the brainstorming teams, is presented in the short BAMS article by Baklanov et al. (2017).

\section{Conclusions and recommendations for future research}

Based on the EuMetChem WGs activities, CCMM symposium (CCMM, 2016) and further discussions (e.g. WWRP, 2015; Baklanov et al., 2017), the following recommendations for future research have been identified.

For meteorological studies and specifically NWP the following research is needed:

Developing diagnostics and validation methodologies to more explicitly separate the different effects of the intertwined feedback processes.
More collaboration between operational centers and research communities. This needs to be focused on providing schemes that have an impact that is proven to be valuable enough to justify the cost of their implementation (even for relatively modest increases in CPU).

More evaluation of aerosol properties routinely, not only for the indicators $\mathrm{PM}_{10}$ and $\mathrm{PM}_{2.5}$ but also for optical, chemical and microphysical properties.

The treatment of the indirect effect of aerosols is one of the key uncertainties; ice nucleation processes and parameterizations are less well defined than $\mathrm{CCN}$ parameterizations.

Further research is needed to better understand the importance of including more accurate representation of aerosol properties in satellite retrievals.

Research on the impact of online modeling of aerosols on visibility forecasting, observational constraints on the causes of light extinction and on parameterizations for calculating extinction given model parameters.

For air quality and atmospheric composition studies the following research needs are stressed:

Experiments that are specifically defined to look at chemistry-cloud-microphysics at different scales.

More field experimental data to evaluate online coupled models.

Improved numerical and computational efficiency of the models as the complexity of applications grows (e.g., scales).

Intercomparizons both at global and regional/urban scale for AQ, NWP and climate should continue; intercomparizons that are cutting across all 3 fields should be considered.

For climate research the following main developments in CCMMs are needed:

Improve our understanding of indirect effects (e.g. BC on clouds).

Develop CCMs with prognostic aerosols to assess what is the tradeoff between a more complex aerosol representation on the one side and model resolution, or the atmosphereocean coupling, on the other side?

Test model performance in terms of relevant physical, chemical, and radiative processes and mechanisms (in contrast to just testing mean performance).

Test model performance in terms of tropospheric dynamics/meteorology and their effect on composition (and viceversa).

Acknowledgements. The COST Office, which funded and supported the Action ES1004 EuMetChem, and the World Meteorological Organization, which organized the CCMM Symposium, are greatly acknowledged. The author thanks the EuMetChem cochairs, WG leaders and all the participants of the COST Action ES1004 EuMetChem and CCMM Symposium for joint work and contributions to the EuMetChem and Symposium outcomes. 


\section{References}

Baklanov, A., Vogel, B., and Freitas, S. (Eds.): Coupled chemistrymeteorology modelling: status and relevance for numerical weather prediction, air quality and climate communities (SI of EuMetChem COST ES1004) (ACP/GMD inter-journal SI), Atmos. Chem. Phys., http://www.atmos-chem-phys.net/special_ issue 370.html, 2013.

Baklanov, A., Schlünzen, K., Suppan, P., Baldasano, J., Brunner, D., Aksoyoglu, S., Carmichael, G., Douros, J., Flemming, J., Forkel, R., Galmarini, S., Gauss, M., Grell, G., Hirtl, M., Joffre, S., Jorba, O., Kaas, E., Kaasik, M., Kallos, G., Kong, X., Korsholm, U., Kurganskiy, A., Kushta, J., Lohmann, U., Mahura, A., Manders-Groot, A., Maurizi, A., Moussiopoulos, N., Rao, S. T., Savage, N., Seigneur, C., Sokhi, R. S., Solazzo, E., Solomos, S., Sørensen, B., Tsegas, G., Vignati, E., Vogel, B., and Zhang, Y.: Online coupled regional meteorology chemistry models in Europe: current status and prospects, Atmos. Chem. Phys., 14, 317-398, doi:10.5194/acp-14-317-2014, 2014.

Baklanov, A., Brunner, D., Carmichael, G., Flemming, J., Freitas, S., Gauss, M., Hov, Ø., Mathur, R., Schlünzen, K. H., Seigneur, C., and Vogel, B.: Key issues for seamless integrated chemistrymeteorology modeling, B. Am. Meteorol. Soc., in press, 2017.
CCMM: Coupled Chemistry-Meteorology/Climate Modelling (CCMM): status and relevance for numerical weather prediction, atmospheric pollution and climate research (Symposium materials), WMO GAW Report \#226, WMO, Geneva, Switzerland, March 2016, available at: https://www.wmo.int/pages/prog/ arep/gaw/documents/Final_GAW_226_10_May.pdf (last access: 5 May 2017), 2016.

Galmarini, S. and Hogrefe, C. (Eds.): Evaluating Coupled Models (AQMEII P2). Special Issue Section, Atmos. Environ., 115, 340 775, 2015.

Galmarini, S., Hogrefe, C., Brunner, D., Makar, P., Baklanov, A.: Evaluating Coupled Models (AQMEII P2), Preface, Atmos. Environ., 15, 340-344, doi:10.1016/j.atmosenv.2015.06.009, 2015.

Miranda, A. I., Monteiro, A., Martins, H., Baklanov, A., and Schluenzen, K. H.: Online Integrated Modelling of Meteorological and Chemical transport Processes. EUMETCHEM Young Scientists Summer School Education Book, COST Action ES1004, University of Aveiro, WMO, University of Hamburg, 132 pp., 2014.

WWRP: Seamless Prediction of the Earth System: from Minutes to Months, WMO-No. 1156, available at: http://library.wmo.int/ pmb_ged/wmo_1156_en.pdf (last access: 5 May 2017), 2015. 